\title{
Transformation of tetrachloroethylene in a flow-through electrochemical reactor
}

Hyldegaard, Bente Højlund; Ottosen, Lisbeth M.; Alshawabkeh, Akram N.

\section{Published in:}

Science of the Total Environment

Link to article, DOI:

10.1016/j.scitotenv.2019.135566

Publication date:

2020

Document Version

Peer reviewed version

Link back to DTU Orbit

Citation (APA):

Hyldegaard, B. H., Ottosen, L. M., \& Alshawabkeh, A. N. (2020). Transformation of tetrachloroethylene in a flowthrough electrochemical reactor. Science of the Total Environment, 707, [135566].

https://doi.org/10.1016/j.scitotenv.2019.135566

\section{General rights}

Copyright and moral rights for the publications made accessible in the public portal are retained by the authors and/or other copyright owners and it is a condition of accessing publications that users recognise and abide by the legal requirements associated with these rights.

- Users may download and print one copy of any publication from the public portal for the purpose of private study or research.

- You may not further distribute the material or use it for any profit-making activity or commercial gain

- You may freely distribute the URL identifying the publication in the public portal

If you believe that this document breaches copyright please contact us providing details, and we will remove access to the work immediately and investigate your claim 

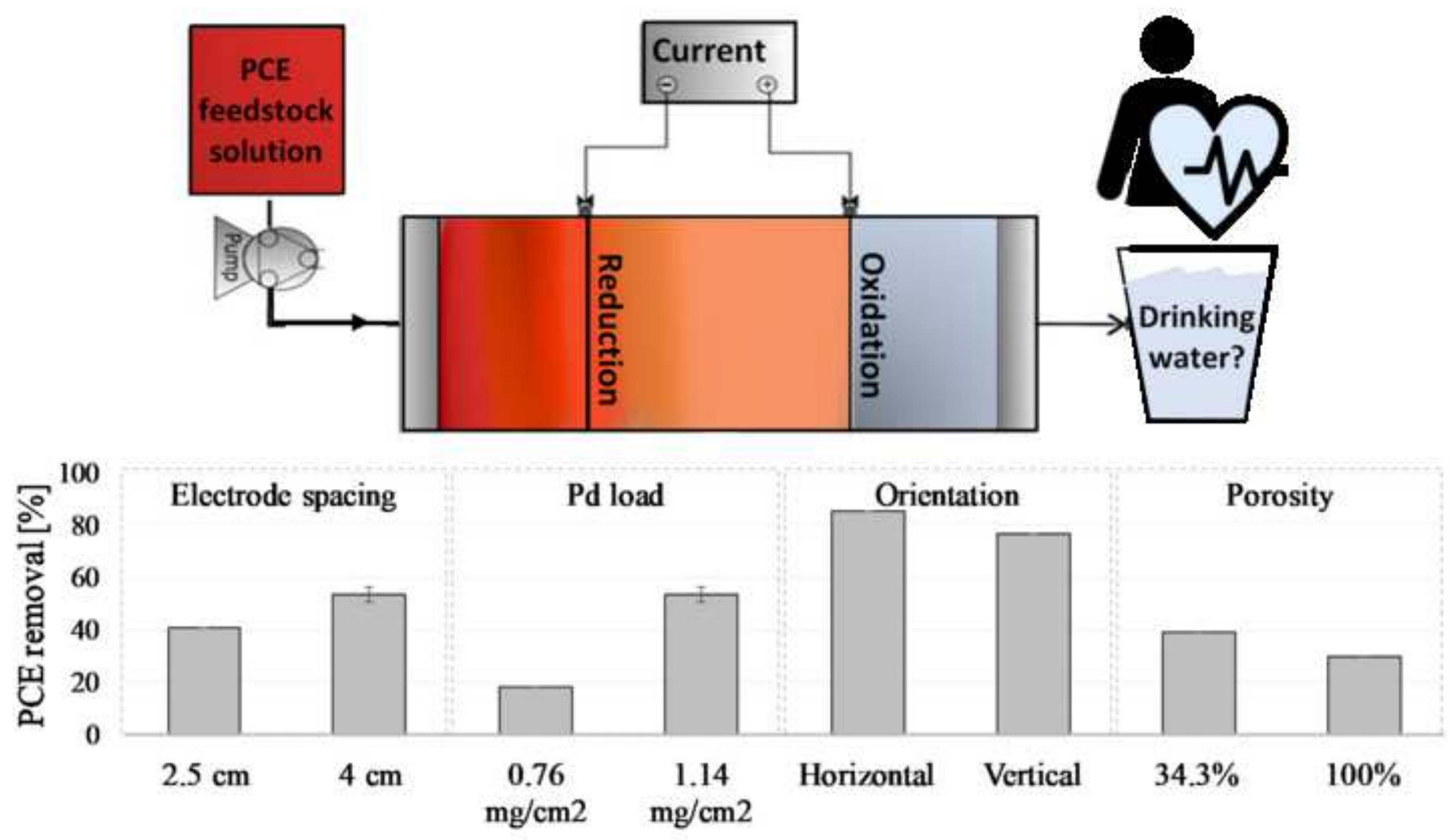


\section{Highlights}

- Harmful chlorinated ethenes threaten the drinking water resource and its consumers

- Transformation of PCE in electrochemical flow-through reactors was studied

- Influence of various reactor design parameters was investigated, reaching $86 \%$ removal

- Normalization of data improved understanding of mechanisms across tests and studies

- Electrochemical reduction and oxidation can reduce mass flux of simulated PCE plumes 


\section{Transformation of tetrachloroethylene in a flow-through}

\section{2 electrochemical reactor}

4 Bente H. Hyldegaard ${ }^{\text {a, b, c, }{ }^{*} \text {, Lisbeth M. Ottosen }}{ }^{\text {b }}$, Akram N. Alshawabkeh ${ }^{\text {c }}$

${ }^{a}$ Department of Waste \& Contaminated Sites, COWI, Parallelvej 2, 2800 Kgs. Lyngby, Denmark

${ }^{b}$ Department of Civil Engineering, Brovej, Building 118, Technical University of Denmark, 2800 Kgs. Lyngby, Denmark.

$9{ }^{c}$ Department of Civil \& Environmental Engineering, 501 Stearns, 360 Huntington Avenue, Boston, MA 02115, United States of America.

*Corresponding author.E-mail address: behd@cowi.com /benho@byg.dtu.dk(B.H. Hyldegaard).

\section{Abstract}

Electrochemical transformation of harmful tetrachloroethylene (PCE) is evaluated as a method for management of groundwater plumes to protect the drinking water resource, its consumers and the environment. In contrast to previous work that reported transformation of trichloroethylene, a byproduct of PCE, this work focuses on transformation of PCE in a saturated porous matrix and the influence of design parameters on the removal performance. Design parameters investigated were electrode configuration, catalyst load, electrode spacing, current intensity, orientation of reactor and flow through a porous matrix. A removal of $86 \%$ was reached in the fully liquid-filled, horizontally oriented reactor at a current of $120 \mathrm{~mA}$ across a cathode $\rightarrow$ bipolar electrode $\rightarrow$ anode arrangement with a Darcy velocity of $0.03 \mathrm{~cm} / \mathrm{min}(150 \mathrm{~m} / \mathrm{yr})$. The palladium load on the cathode significantly 
8

influenced the removal. Enhanced removal was observed with increased electrode spacing. Presence of an inert porous matrix improved PCE removal by 9\%-point compared to a completely liquid-filled reactor. Normalization of the data indicated, that a higher charge transfer per contaminant mass is required for removal of low PCE concentrations. No chlorinated intermediates were formed. The results suggest, that PCE can be electrochemically transformed in reactor designs replicating that of a potential field-implementation. Further work is required to better understand the reduction and oxidation processes established and the parameters influencing such. This knowledge is essential for optimization towards testing in complex conditions and variations of contaminated sites.

\section{Keywords}

Chlorinated ethenes, removal, groundwater, electrochemistry, design screening

\section{Introduction}

9

(1)
and harmful contamination of the subsurface, potentially impacting the groundwater and indoor air quality $[1,2]$. Effort has been put into remediation of low-permeable zones, where use of electrokinetics has shown to overcome some of the challenges faced [3-7]. However, the dense chlorinated ethenes slowly leak into aquifers, causing an increase in detection above regulatory maximum contaminant levels [8]. Current remedies used for chlorinated ethene plumes include pump-and-treat $[9,10]$, enhanced reductive dechlorination $[1,10]$, in-situ chemical oxidation $[11,12]$, permeable reactive barriers $[13,14]$ and air-sparging $[15,16]$. These technologies can be challenged 

$\square \mathrm{OH}$ radicals (Eq. 3), which also oxidize the chlorinated ethenes [34].
60

61

by inadequate delivery of reactants $[12,17,18]$, short longevity of reactants $[12,19,20]$ or varying contaminant phase transfer affinities with generation of contaminated waste [16,21]. Challenges, which may be overcome by adaptation of the mechanisms of electrokinetics towards mass flux reduction in these high-permeable zones by establishment of electrochemical zones. This is gaining increasing focus, since reducing and oxidizing zones sufficient for degradation of the chlorinated ethenes can be established [22-25]. The reducing zone is generated from electrolysis at the cathode (Eq. 1) $[26,27]$, which can directly and indirectly reduce the parent components tetrachloroethylene (PCE) and trichloroethylene (TCE) and stimulate microbial degradation [28-31]. In addition, hydrogen peroxide $\left(\mathrm{H}_{2} \mathrm{O}_{2}\right)$, which is a strong oxidant that can break down the chlorinated ethenes [32,33], can be effectively formed (Eq. 2) at a sufficiently high dissolved oxygen concentration, or if a catalyst like palladium $(\mathrm{Pd})$ is applied to the cathode. Furthermore, $\mathrm{Pd}$ can catalyze formation of

1

The anode generates oxidizing conditions (Eq. 4) [26], specifically by $\mathrm{Ti} / \mathrm{IrO}_{2}-\mathrm{Ta}_{2} \mathrm{O}_{5}$ mixed metal oxide (MMO) anodes (Eq. 5) [35], which can oxidize e.g. TCE and the chlorinated intermediates dichloroethylene (DCE) and vinyl chloride (VC). However, the oxygen evolution competes with oxidation of the chlorinated ethenes. 


$$
\begin{gathered}
2 \mathrm{H}_{2} \mathrm{O} \rightarrow \mathrm{O}_{2}+4 \mathrm{H}^{+}+4 \mathrm{e}^{-} \\
\mathrm{IrO}_{3}+\mathrm{H}_{2} \mathrm{O} \leftrightarrow \mathrm{IrO}_{2}+\mathrm{O}_{2}+2 \mathrm{H}^{+}+2 \mathrm{e}^{-}
\end{gathered}
$$

66

Research on electrochemical removal of chlorinated ethenes has focused on TCE [22,23,3944,24,28,32,34-38]. Since TCE is more volatile than PCE, mass balances of TCE can be particularly poor. Also, the reported optimal design parameters are dependent on the specific system studied, and little knowledge is available on the specific mechanisms responsible for degradation of PCE and TCE in flow-through electrochemical reactors. This makes it complex to adapt the current level of knowledge on electrochemical removal of TCE towards complete removal of PCE. The reduction mechanisms have been investigated on iron metal $(\mathrm{Fe}(0))$ surfaces, showing higher dechlorination rates with increased halogenation [45-47], but also the opposite trend [48-50]. Arnold and Roberts [49] found, that $87 \%$ of PCE and 97\% of TCE follow direct reduction on $\mathrm{Fe}(0)$, i.e. contact between the surface of $\mathrm{Fe}(0)$ and the chlorinated ethene is essential. During direct reduction on $\mathrm{Fe}(0)$ surfaces, the reaction rate constant for PCE is higher than that for TCE [51]. While during indirect reduction via atomic hydrogen formed from electrolysis (Eq. 1) [51], the reaction rate constant for PCE is lower than that for TCE. Thus, a smaller fraction of PCE than TCE follows the direct reduction pathway, but reaction kinetics is faster during direct reduction of PCE than TCE. The rate limiting steps for direct and indirect reduction are chemisorption onto the electrode, electron transfer, bond-breaking or molecular rearrangement [52].

Competing reactions, due to presence of ionic species in the electrolyte, can interfere with the chemical mechanisms responsible for removal of the chlorinated ethenes, which may be nonlinearly distributed, and time and space dependent. This may explain observed variations over time, the course of reactors and between batch and column set-ups [51,53]. In addition, electrode 
compositions and impurities influence the reduction processes $[49,54,55]$. For development of flexible full-scale remediation designs that can overcome the complexity and variations of contaminated sites, improved understanding of the transformation mechanisms and parameters controlling those is essential.

The objective of this study is to examine the influence of reactor design on the electrochemical removal of PCE in a flow-through reactor using palladized Fe foam cathodes and MMO anodes. The study is a screening of the significance of parameters relevant to a field design on the electrochemical PCE removal performance, e.g. a porous matrix and horizontal orientation. Such knowledge is required for development of a more robust test design for enhanced applicability and feasibility testing at conditions simulating that of potential in-situ applications. Previous work has studied electrochemical removal of mainly TCE in static reactors [37,56], stirred reactors $[22,57]$, recirculated reactors $[23,35,40]$, vertical flow-through reactors $[24,34,41-44,56,58]$, applied constant voltage $[39,59,60]$ or studied electrochemistry in combination with other remediation strategies, e.g. bioremediation [29,61-64]. Assessment of the potential of flow-through electrochemical transformation of PCE is important to cover the full range of chlorinated ethene species detected at contaminated sites. This study differs from previous work by studying the electrochemical removal of PCE in horizontally oriented undivided reactors with flow through a porous matrix and operated at constant current. Studying such a reactor design is a necessary step towards upscaling of electrochemical remediation for treatment of contaminated groundwater. In the field, the primary groundwater flow direction is horizontal, flow is through a porous matrix, and the charge transfer is best controlled with application of constant current.

\section{Materials and methods}




\subsection{Chemicals and materials}

Chemicals used were of analytical grade: PCE (99\%, Sigma-Aldrich), TCE (99.5\%, SigmaAldrich), cis-DCE (97\%, Sigma-Aldrich), calcium sulfate (JT Baker), hydrochloric acid (HCl) (37\%, Carolina) and palladium(II) chloride ( $\mathrm{PdCl}_{2}, 99.9 \%$, Alfa Aesar). MMO meshes (1.8 mm in width, $3 \mathrm{~N}$ International), composed of $\mathrm{IrO}_{2}$ and $\mathrm{Ta}_{2} \mathrm{O}_{5}$ coating on titanium were used as bipolar electrodes (BPE) and anodes. Cathodes of $\mathrm{Fe}$ foam ( $3 \mathrm{~mm}$ in width, 45 pores per inch, $98 \% \mathrm{Fe}, 2 \%$ $\mathrm{Ni}$, Aibixi Ltd.) and/or 316 stainless steel discs (SS, $0.7 \mathrm{~mm}$ in width, $0.4 \mathrm{~mm}$ wire diameter, $20 \mathrm{x}$ 20 mesh size, $0.86 \mathrm{~mm}$ opening size, $12 \% \mathrm{Ni}$, McMaster-Carr) were used. The diameter of electrodes used was $77 \mathrm{~mm}$. The $316 \mathrm{SS}$ cathode was assembled using four discs to increase the width. Fe foam cathodes were perforated with $4 \mathrm{~mm}$ holes for every $10 \mathrm{~mm}$ and coated with Pd. Prior to electroless plating with $\mathrm{Pd}$, the $\mathrm{Fe}$ foam was rinsed in $1 \mathrm{M} \mathrm{HCl}$ for 10 minutes, thoroughly washed in deionized water, submerged in a solution of $0.1 \mathrm{M} \mathrm{HCl}$ and $\mathrm{PdCl}_{2}$, rotated until the orange solution turned colorless and washed with deionized water [41,42]. Solid glass beads $(5 \mathrm{~mm}$, $\left.2.23 \mathrm{~g} / \mathrm{cm}^{3}\right)$ were purchased from Propper Manufacturing Co. Inc. Nylon meshes $(0.1 \mathrm{~mm}$ in width, $0.12 \mathrm{~mm}$ wire diameter, 61 x 61 mesh size, $0.3 \mathrm{~mm}$ opening size, McMaster-Carr) were mounted on each side of the electrodes to prevent glass beads in blocking openings of the electrode meshes. Feedstock solutions were stored in Tedlar® bags (Sigma-Aldrich) and prepared using 18.2 M $\Omega \mathrm{cm}$ high-purity water from a Millipore Milli-Q system. Tygon ${ }^{\circledR}$ tubing (2.06 mm ID, 3.79 mm OD, Cole-Parmer) and a peristaltic pump (0.4-85 $\mathrm{ml} / \mathrm{min}$, Cole-Parmer), were used to control the flow of liquid. Constant current was applied using one Agilent E3612A 0-120V, 0-0.25 A power supply.

\subsection{Analytical methods}



720-ES. Samples were filtrated prior to analysis using 0.2 $\mu \mathrm{m}$ PVDF syringe filters from Jin Teng. Conductivity of the feedstock solutions was measured using a Thermo Orion 5 Star meter with corresponding probe. $\mathrm{pH}$ of the feedstock solutions was measured using a Mettler Toledo Seven Compact meter with corresponding probe. $\mathrm{pH}$ of samples collected from sampling ports was assessed using EMD Millipore ${ }^{\mathrm{TM}}$ MColorpHast $^{\mathrm{TM}} \mathrm{pH}$ test strips.

\subsection{Electrochemical flow-through reactor}

Synthetic groundwater simulating the conductivity of a sandy aquifer was prepared by dissolving carbonate to limit the influence of the carbonate system on the electrochemical mechanisms and $\mathrm{pH}$ gradients established [65]. The resulting conductivity was $700-890 \mu \mathrm{S} / \mathrm{cm}$ with a $\mathrm{pH}$ of $5.7 \pm 0.4$

Table 1. Experimental conditions for the electrochemical treatment of initially $2.7 \mathrm{mg} / \mathrm{l} \mathrm{PCE}$.

\begin{tabular}{|c|c|c|c|c|c|c|c|}
\hline Electrode & Electrode material & Electrode & Column & Current & Pd catalyst & Darcy & Porosity, \\
\hline \multirow[t]{2}{*}{ configuration $^{\mathrm{a}}$} & & spacing & orientation & {$[\mathrm{mA}]$} & loading $^{\mathrm{b}}$ & velocity & water- \\
\hline & & {$[\mathrm{cm}]$} & & & {$\left[\mathrm{mg} / \mathrm{cm}^{2}\right]$} & {$[\mathrm{cm} / \mathrm{min}]$} & filled $^{\mathrm{c}}[\%]$ \\
\hline
\end{tabular}




\begin{tabular}{|c|c|c|c|c|c|c|c|c|}
\hline $0^{\mathrm{d}}$ & $\mathrm{C} \rightarrow \mathrm{BPE} \rightarrow \mathrm{A}$ & $\mathrm{Fe}$ foam $\rightarrow \mathrm{MMO} \rightarrow \mathrm{MMO}$ & 4 & Horizontal & 0 & 0.76 & 0.09 & $31.1 \pm 0.3$ \\
\hline 1 & $\mathrm{C} \rightarrow \mathrm{BPE} \rightarrow \mathrm{A}$ & $\mathrm{Fe}$ foam $\rightarrow \mathrm{MMO} \rightarrow \mathrm{MMO}$ & 4 & Horizontal & 60 & 0.76 & 0.09 & 30.8 \\
\hline 2 & $\mathrm{C} \rightarrow \mathrm{BPE} \rightarrow \mathrm{A}$ & $\mathrm{Fe}$ foam $\rightarrow \mathrm{MMO} \rightarrow \mathrm{MMO}$ & 4 & Horizontal & 120 & 0.76 & 0.09 & 30.8 \\
\hline $3^{d}$ & $\mathrm{C} \rightarrow \mathrm{BPE} \rightarrow \mathrm{A}$ & $\mathrm{Fe}$ foam $\rightarrow \mathrm{MMO} \rightarrow \mathrm{MMO}$ & 4 & Horizontal & 120 & 1.14 & 0.08 & $34.8 \pm 0.5$ \\
\hline 4 & $\mathrm{C} \rightarrow \mathrm{BPE} \rightarrow \mathrm{A}$ & $\mathrm{Fe}$ foam $\rightarrow \mathrm{MMO} \rightarrow \mathrm{MMO}$ & 4 & Horizontal & 180 & 1.14 & 0.08 & 35.3 \\
\hline 5 & $\mathrm{C} \rightarrow \mathrm{BPE} \rightarrow \mathrm{A}$ & $\mathrm{Fe}$ foam $\rightarrow \mathrm{MMO} \rightarrow \mathrm{MMO}$ & 2.5 & Horizontal & 120 & 1.14 & 0.08 & 34.1 \\
\hline 6 & $\mathrm{C} \rightarrow \mathrm{BPE} \rightarrow \mathrm{A}$ & $\mathrm{Fe}$ foam $\rightarrow \mathrm{MMO} \rightarrow \mathrm{MMO}$ & 4 & Horizontal & 120 & 1.14 & 0.03 & 100 \\
\hline 7 & $\mathrm{C} \rightarrow \mathrm{BPE} \rightarrow \mathrm{A}$ & $\mathrm{Fe}$ foam $\rightarrow \mathrm{MMO} \rightarrow \mathrm{MMO}$ & 4 & Vertical & 120 & 1.14 & 0.03 & 100 \\
\hline 8 & $\mathrm{C} \rightarrow \mathrm{C} \rightarrow \mathrm{A}$ & $\mathrm{SS} \rightarrow \mathrm{Fe}$ foam $\rightarrow \mathrm{MMO}$ & 4 & Horizontal & 120 & 1.14 & 0.08 & 34.2 \\
\hline 9 & $\mathrm{C} \rightarrow \mathrm{C} \rightarrow \mathrm{A}$ & $\mathrm{Fe}$ foam $\rightarrow \mathrm{Fe}$ foam $\rightarrow \mathrm{MMO}$ & 4 & Horizontal & 120 & 1.14 & 0.08 & 35.0 \\
\hline 10 & $\mathrm{C} \rightarrow \mathrm{A}$ & Fe foam $\rightarrow$ MMO & 8 & Horizontal & 120 & 1.14 & 0.08 & 34.3 \\
\hline 11 & $\mathrm{C} \rightarrow \mathrm{A}$ & $\mathrm{Fe}$ foam $\rightarrow \mathrm{MMO}$ & 2.5 & Horizontal & 120 & 1.14 & 0.25 & 100 \\
\hline 12 & $\mathrm{C} \rightarrow \mathrm{A}$ & $\mathrm{Fe}$ foam $\rightarrow \mathrm{MMO}$ & 2.5 & Vertical & 120 & 1.14 & 0.25 & 100 \\
\hline
\end{tabular}

${ }^{a}$ A: Anode, C: Cathode, BPE: Bipolar electrode

$158{ }^{\mathrm{b}}$ Catalyst applied on Fe foam only. Load is given as mass per geometric electrode surface area

$159{ }^{\mathrm{c}}$ Porosities of $100 \%$ indicate a fully liquid-filled reactor, while tests with porosities $<100 \%$ incorporate the porous matrix

$160{ }^{\mathrm{d}}$ Duplicate testing

An acrylic column was used as the flow-through electrochemical reactor (L $16.8 \mathrm{~cm}$ and D 7.8 investigated in a sequence of a) electrode configurations and spacings. For three-electrode configurations, the constant current was split equally between the two cathodes by a rheostat, $b$ ) current intensities and Pd catalyst loadings, c) porous matrices and reactor orientations. The inert porous matrix was incorporated to replicate field-conditions and to reduce amount of contaminated waste generated, and d) groundwater flow and test duration (Table 1).

The position of electrodes and sampling ports (P0-P5) in the electrochemical reactor is shown in Figure 1. In horizontally orientated reactors, electrolytically generated gases were extracted manually from sampling ports above the electrodes using syringes with needles. To limit mass loss 
by volatilization, the gas extraction occurred whenever a gas phase was observed. The frequency of

173 this manual venting depended on current intensity, electrode configuration and electrode material

174

175 176

177 178 179 180 181 182 with a range of once every 30-90 seconds. In vertically oriented reactors, released gases moved up through the reactor and out with the effluent.

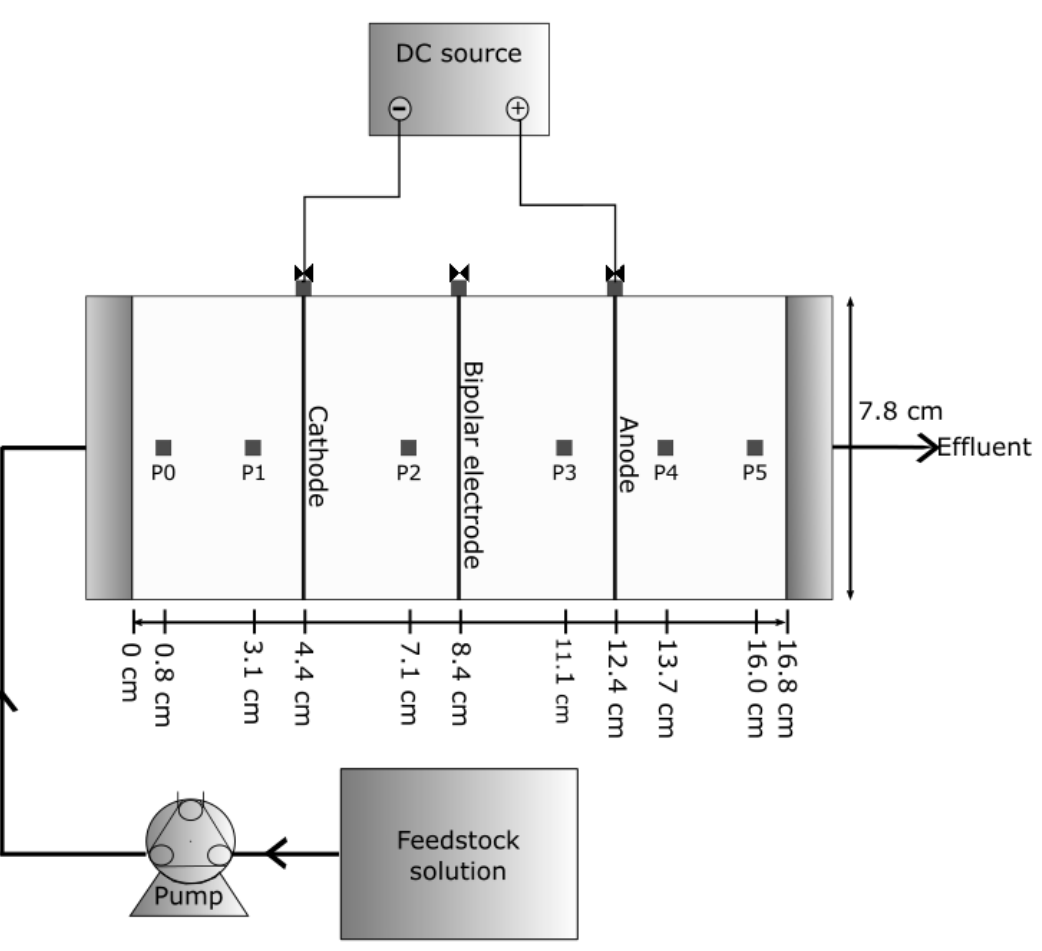

Figure 1. The baseline flow-through electrochemical set-up composed of a feedstock solution, peristaltic pump, a cathode, bipolar electrode and an anode connected to a power supply. P0-P5 are sampling ports. Sampling ports above the electrodes served for manual extraction of gases generated. Measures are of inner dimensions.

Prior to the electrochemical application, the reactor was saturated with the feedstock solution at elevated flow to limit volatilization, followed by flow-through for one pore volume (PV) at the flow velocities given in Table 1 to ensure a uniform contaminant distribution. Direct current was applied for 3.5 PV and 1.2 PV for flow through the porous matrix (Table 1, test 1-5, 8-10) and completely liquid-filled reactor (Table 1, test 6-7, 11-12), respectively. 


\section{Results and discussion}

190

Different designs of the electrochemical reactor were tested. To evaluate the influence of a

design parameters on the PCE removal, each experiment conducted is compared to similar ones of which one parameter varied only. Accordingly, the significance of electrode spacing, electrode configuration, current intensity, Pd loading on the cathode, duration of electrochemical treatment, orientation of reactor and porosity on PCE removal, potential difference over the electrodes and $\mathrm{pH}$ downstream of the electrochemical zone is assessable (Figure 2). The design parameter category, e.g. electrode spacing, is indicated above comparable experiments, whereas the specific dimension of that design parameter, e.g. $2.5 \mathrm{~cm}$ and $4 \mathrm{~cm}$, is given on the horizontal axis. Figures written on the bars refer to the experimental numbers given in Table 1.

\subsection{Impact of electrode configuration and spacing on PCE removal}

Influence of electrode configuration and spacing on electrochemical removal of PCE was investigated in the flow-through reactor with Fe and MMO electrodes at $120 \mathrm{~mA}$ and a Darcy velocity of $0.08 \mathrm{~cm} / \mathrm{min}$ (experiments 3,5,8-10, Figure 2a, Table 1).

A three-electrode configuration of two Pd coated Fe foam cathodes and an MMO anode performed similar to the corresponding two-electrode configuration, reaching removals of $42 \%$ and 39\%, respectively (exp. 9-10, Figure 2a). Rajic et al. [41] also observed comparable removals of TCE in two- and three-electrode configured reactors using Fe and MMO electrodes, while the reaction rate nearly doubled in the three-electrode arrangement. By replacing the first $\mathrm{Pd} / \mathrm{Fe}$ foam cathode with 316 SS, the removal increased to $51 \%$ (exp. 8, Figure 2a). The high content of Ni in 
this type of stainless steel can catalyze reduction, since Ni like Pd lowers the cathodic hydrogen overpotential [55,66], enhancing the hydrodechlorination. Use of Ni-containing stainless steels for electrochemical removal of chlorinated ethenes has shown to be cost-efficient [55]. The best performing electrode configuration was $\mathrm{C} \rightarrow \mathrm{BPE} \rightarrow \mathrm{A}$ with a removal of $54 \pm 3 \%$ (exp. 3, Figure 2a). By introducing a BPE, a supplementary oxidizing-reducing zone is established, enhancing the hydrodechlorination and oxidation by increased formation of $\mathrm{H}_{2} \mathrm{O}_{2}$ (Eq. 2) [34]. Of the electrode configurations and materials tested, the lowest potential difference of $17 \mathrm{~V}$ was obtained in the 316 $\mathrm{SS} \rightarrow \mathrm{Pd} / \mathrm{Fe} \rightarrow \mathrm{MMO}$ arrangement, and the highest potential difference of $36 \mathrm{~V}$ in the $\mathrm{Pd} / \mathrm{Fe} \rightarrow$ MMO reactor (exp. 8 and 10, Figure 2b). The BPE lowered the potential difference from $36 \mathrm{~V}$ to $32 \mathrm{~V}$ (exp. 3 and 10, Figure 2b); a simple measure to potentially reduce the costs of power consumption in upscaling activities.

Increasing the electrode spacing from $2.5 \mathrm{~cm}$ to $4 \mathrm{~cm}$ in the $\mathrm{C} \rightarrow \mathrm{BPE} \rightarrow \mathrm{A}$ arrangement improved the PCE removal from $41 \%$ to $54 \pm 3 \%$ (exp. 3 and 5, Figure 2a). This is opposite to previous findings in completely liquid-filled reactors, where the observed decrease in removal with an increase in electrode spacing was explained by a resulting increase in potential difference over the reactor [41]. In this study, the potential difference also increased, from $22 \mathrm{~V}$ to $31.6 \pm 0.4 \mathrm{~V}$ (exp. 3 and 5, Figure 2b), and thereby the resistivity of the system [67], but the increase did not inhibit the removal as previously shown for TCE [41,68]. By increasing the electrode spacing, the redox zone is prolonged, which possibly accounts for the increased PCE removal. Considering upscaling, this can reduce the direct costs for the plant due to a cutback in the network of electrodes.

$\mathrm{pH}$ measured in the porewater downgradient the electrochemical zone (sampling port P5) was 4.5-5 in the $\mathrm{C} \rightarrow \mathrm{C} \rightarrow \mathrm{A}$ and $\mathrm{C} \rightarrow \mathrm{A}$ configurations tested (exp. 8-10, Figure 2c). For $\mathrm{C} \rightarrow \mathrm{BPE} \rightarrow$ A, $\mathrm{pH}$ was $8.5 \pm 1.5$ (exp. 3, Figure 2c). The elevated $\mathrm{pH}$ in the latter configuration could be due to enhanced $\mathrm{H}_{2} \mathrm{O}_{2}$ formation when introducing a BPE: free oxygen and hydrogen ions generated at 
anodic sites (Eq. 4) are consumed at adjacent cathodic sites (Eq. 2), i.e. the acidic gradient is weakened and incapable of neutralizing the alkaline gradient established at cathodic sites. BPEs have shown to significantly assist in $\mathrm{H}_{2} \mathrm{O}_{2}$ formation in electrochemical flow-through reactors [34]. For comparison, $\mathrm{pH}$ in the control experiment without applied current was 7 (exp. 0, Figure 2c).

\subsection{Significance of current intensity and catalyst loading on PCE removal}

Currents of $0 \mathrm{~mA}, 60 \mathrm{~mA}, 120 \mathrm{~mA}$ and $180 \mathrm{~mA}$ were tested in the $\mathrm{C} \rightarrow \mathrm{BPE} \rightarrow \mathrm{A}$ arrangement for electrochemical removal of PCE with Pd catalyst loadings on the Fe foam cathode of 0.76 $\mathrm{mg} / \mathrm{cm}^{2}$ and/or $1.14 \mathrm{mg} / \mathrm{cm}^{2}$ (exp. 0-4, Figure 2a).

For catalyst loadings of $0.76 \mathrm{mg} / \mathrm{cm}^{2}$, PCE removals were $0 \%, 14 \%$ and $18 \%$ at currents of 0 mA, $60 \mathrm{~mA}$ and $120 \mathrm{~mA}$, respectively (exp. 0-2, Figure 2a). For catalyst loadings of $1.14 \mathrm{mg} / \mathrm{cm}^{2}$, PCE removals were 54+3\% and 39\% at $120 \mathrm{~mA}$ and $180 \mathrm{~mA}$, respectively (exp. 3-4, Figure 2a). Thus, the current intensity and PCE removal are parabolic correlated. The decline in removal at 180 $\mathrm{mA}$ is explained by increased competition of oxygen evolution at the anode. In addition, the oxygen generated physically covered the anode and thereby occupied active sites for oxidation $[41,42]$.

Catalysts are important for the transformation of PCE, since a 50\% increase in Pd load enhanced PCE removal by 36\%-point at $120 \mathrm{~mA}$ (exp. 2-3, Figure 2a). The significance of Pd on chlorinated ethene removal has been studied previously, where an optimal concentration of $0.76 \mathrm{mg} / \mathrm{cm}^{2}$ was found [42]. The inconsistency in findings of optimal load of Pd on Fe foam cathodes possibly is associated with the geometry of the Fe foam cathodes used; the electrode surface areas tend to be estimated based on geometrical shape, since the actual surface area of the foams is unknown. Thus, the electrode surface area ratio between experimental set-ups cannot be applied directly in the dimensioning of Pd load. 
In the set-up studied, a further increase in Pd load could optimize the removal performance, since 261 the $\mathrm{C} \rightarrow \mathrm{C} \rightarrow \mathrm{A}$ arrangement with $316 \mathrm{SS}$ and $\mathrm{Pd} / \mathrm{Fe}$ foam cathodes was superior to two $\mathrm{Pd} / \mathrm{Fe}$ foam cathodes (Section 3.1., exp. 8-9, Figure 2a), with higher catalytic content in the 316 SS than the resulting palladization. However, replacing the $\mathrm{Pd} / \mathrm{Fe}$ foam cathode with $316 \mathrm{SS}$ in a $\mathrm{C} \rightarrow \mathrm{A}$ set-up is insufficient [55]. In the remainder of tests, a Pd load of $1.14 \mathrm{mg} / \mathrm{cm}^{2}$ was applied. The voltage stabilized at $32 \mathrm{~V}$ at $120 \mathrm{~mA}$ independent of Pd load (exp. 2-3, Figure 2b). Whereas the potential difference increased from $20 \mathrm{~V}$ to $32 \mathrm{~V}$ to $38 \mathrm{~V}$ at $60 \mathrm{~mA}, 120 \mathrm{~mA}$ and $180 \mathrm{~mA}$, respectively (exp. 1-4, Figure 2b), a linear correlation with $\mathrm{R}^{2}$ of 0.93 . According to Ohms Law, the electrical resistivity should remain constant when the experimental conditions, besides current intensity, are unaltered. In this study, the resistivity increased with increasing current, which possibly can be ascribed to increased oxygen and hydrogen generation at the anode ((Eq. 4)-(Eq. 5) and cathode (Eq. 1) with increased current. The additional gases formed extended the gas coverage of the electrode surfaces. Evolving gas layers on the electrode surfaces reduce connectivity between electrodes and the conductive liquid phase, wherefore the electrical resistivity increases.

MMO anodes are known to maintain $\mathrm{pH}$ of the water treated [41]. However, in the studied $\mathrm{C} \rightarrow$ $\mathrm{BPE} \rightarrow \mathrm{A}$ arrangement, $\mathrm{pH}$ of the porewater downgradient of the electrochemical zone (sampling port P5) was elevated to $8.5 \pm 1.5$ at $120 \mathrm{~mA}$ and $180 \mathrm{~mA}$ (exp. 0 and 3-4, Figure 2c). The elevated pH post electrochemical treatment indicates formation of $\mathrm{H}_{2} \mathrm{O}_{2}$ (Eq. 2) instead of neutralization of the alkaline front established at cathodic sites.

A concern of using catalysts like Pd and Ni for treatment of water, whether it is for drinking purposes or discharge into the nature, is the release of ions, which may inhibit living organisms $[69,70]$. If the catalyst is applied on the cathode and polarity is not reversed, release is of little concern. Whether Pd is released when no current is applied, is not reported. Therefore, effluent samples extracted throughout the $360 \mathrm{~min}$ of control testing (exp. 0) were analyzed for Pd. 
284 Concentration of Pd was below $0.002 \mathrm{mg} / \mathrm{l}$. Tests on Daphnia magna indicate long-term effects of 285 concentrations $>1 \mathrm{mg} / \mathrm{l}$ [71]. 

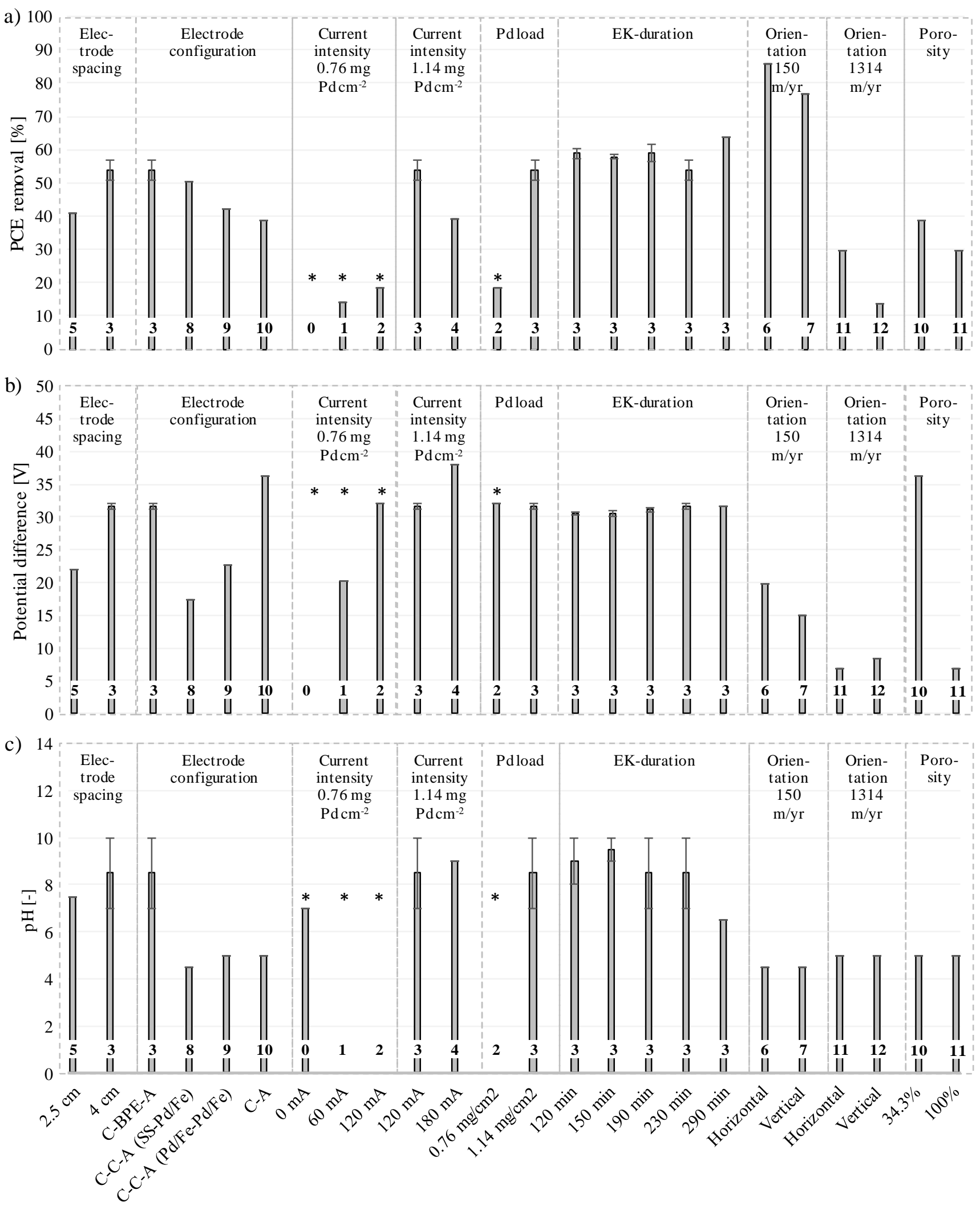

Figure 2. Comparison of the experimental conditions tested on a) PCE removal obtained in sampling port P5, b) potential difference over the reactor measured after app. $1 \mathrm{PV}$ (was rather constant), and c) pH measured in sampling 
port P5. Error bars are included for duplicate testing. * denotes direct reuse of the experimental set-up. Figures on the bars refer to experiment no. in Table 1.

\subsection{Influence of a porous matrix and orientation of reactor on PCE removal}

Electrochemical performance in porous matrices was assessed for flow through a porous matrix of glass beads with a porosity of $34.3 \%$ at a Darcy velocity of $0.08 \mathrm{~cm} / \mathrm{min}$ in the $\mathrm{C} \rightarrow \mathrm{A}$ electrochemical reactor at $120 \mathrm{~mA}$. Presence of the porous matrix enhanced PCE removal to 39\% compared to $30 \%$ in the completely liquid-filled reactor (exp. 10 and 11, Figure 2a). The experimental parameters electrode spacing and flow are varied in this comparison (Table 1, test 1011). Sorption of PCE onto glass beads is neglectable $[32,43]$, verified by the insignificant mass loss in control experiments (exp. 0, Figure 2a). The more complex flow pattern through a porous matrix than a completely liquid-filled reactor may improve the contact between generated reactants and the PCE and explain the enhanced removal in porous matrices. In the porewater downgradient of the electrochemical zone (sampling port P5), pH 5 was measured with and without presence of the porous matrix (exp. 10 and 11, Figure 2c). The potential difference increased from 7V to $36 \mathrm{~V}$ when including the porous matrix (exp. 10 and 11, Figure 2b). Hence, resistivity was 5 times higher in the porous matrix. An increase in potential difference as the alkaline front progresses towards the anode in a porous matrix has been observed [72].

Vertical oriented reactors are applied in most studies on flow-through electrochemical removal of chlorinated ethenes [24,32,58,33,34,40-44,55]. One major advantage is automatic venting of gases generated, since gases released from the electrodes will bubble up through the reactor and leave the reactor with the effluent. For horizontally oriented reactors, the gases will accumulate in a vapor phase above the electrodes, pressurize the system and eventually drain out the fluid, if no 
means of venting are installed. However, a horizontally oriented reactor may be desirable for feasibility studies of field-implementations of electrochemical contaminant transformation in saturated porous matrices. Whether orientation of the reactor influenced the treatment performance was assessed in the $\mathrm{C} \rightarrow \mathrm{BPE} \rightarrow \mathrm{A}$ and $\mathrm{C} \rightarrow \mathrm{A}$ arrangement at $120 \mathrm{~mA}$. At the two flow velocities tested, the horizontally oriented reactor was superior to the vertically oriented with 9-16\%-point (exp. 6 vs. 7 and 11 vs. 12, Figure 2a). pH in the porewater downgradient the electrochemical zone (sampling port P5) was similar in the horizontal and vertical orientations of 4.5 and 5 for the low and high flow velocity studied, respectively (exp. 6-7, 11-12, Figure 2c). For the potential difference over the electrodes, no clear trend is observed (exp. 6-7, 11-12, Figure 2b).

Based on observations, the differences in performance of horizontal and vertical oriented reactors probably were related to the system's ability to release gases generated at the electrodes. In the vertically oriented reactors, the gases accumulated on the upgradient side (lower) of the electrodes until a certain gas volume was reached. The bubbles then pushed through the perforated mesh electrodes and escaped the reactor with the effluent. During the buildup of gases, the potential difference increased followed by a sudden drop once the bubbles had migrated through the mesh electrodes. Accumulation of gases was most prevalent during the high flow tested. Significance of stripping of the volatile contaminant into those gas phases is unknown. In the horizontally oriented reactors, gas phases were immediately extracted above the electrodes using syringes. The gases appeared to be more readily and steadily released and extracted in the horizontal reactors, thus disturbing the system less: the potential difference remained steadier, less pressure build up and the vapor phases were less extensive. Mass loss through volatilization is considered less in the horizontally oriented reactors. Several means of automatic venting in the horizontally oriented reactors were tested; automatic vents, gas-liquid separation membranes, gravity and water-locks. Transient changes in the electrochemical system challenged these venting mechanisms, i.e. the 
manual extraction of gases was most suitable. Venting mechanisms are lab challenges only, because 339 the test set-ups must be closed systems to hinder mass loss through volatilization. In the field, the test area is an open system from which gases can escape through the electrode wells, in which they are generated, or migrate through the soil matrix. If stripping of chlorinated ethenes is an issue, granular activated carbon above the electrodes can capture the volatilized fraction of the contamination.

\subsection{Effect of flow and test duration on PCE removal}

Flow rate is inverse proportional to residence time of PCE within the electrochemical reactor, i.e. lowering the flow rate prolongs the residence time. Effect of flow was studied in the completely liquid-filled reactor with a high flow in the $\mathrm{C} \rightarrow \mathrm{A}$ arrangement (exp. 11-12) and compared to a low flow in the $\mathrm{C} \rightarrow \mathrm{BPE} \rightarrow$ A configuration (exp. 6-7). The experimental parameters electrode spacing, electrode configuration and flow are varied in this comparison (Table 1, test 6-7 vs.11-12), wherefore changes cannot solely be ascribed to altered flow. However, the effect of flow rate on the PCE removal is significant in comparison to the effect from electrode spacing and configuration 354 alone (exp. 6-7,11-12 vs. 3,5,8-10, Figure 2a).

Reducing the Darcy velocity from $0.25 \mathrm{~cm} / \mathrm{min}(1314 \mathrm{~m} / \mathrm{yr})$ to $0.03 \mathrm{~cm} / \mathrm{min}(150 \mathrm{~m} / \mathrm{yr})$ increased PCE removal with 56-63\%-point reaching a removal of $86 \%$. For electrochemical treatment of TCE at $60 \mathrm{~mA}$, a reduction in Darcy velocity from $2628 \mathrm{~m} / \mathrm{yr}$ to $1314 \mathrm{~m} / \mathrm{yr}$ resulted in a 31\%-point improvement in TCE removal to $87 \%$ [41]. The low flow in the present investigation is representative of common aquifer flows at contaminated sites.

$\mathrm{pH}$ of the porewater downgradient the electrochemical zone (sampling port P5) was similar of 
flow (exp. 6-7 vs. 11-12, Figure 2b), i.e. the resistivity of the high-flow system was lower, indicating a higher mass-transfer of ionic species.

Electrochemical treatment during $120 \mathrm{~min}$ and $290 \mathrm{~min}$ insignificantly influenced the PCE removal, $\mathrm{pH}$ in porewater downgradient the electrochemical zone (sampling port P5) and the potential difference over the electric field in the $\mathrm{C} \rightarrow \mathrm{BPE} \rightarrow \mathrm{A}$ configuration at $120 \mathrm{~mA}$ and a Darcy velocity of $0.08 \mathrm{~cm} / \mathrm{min}$ (exp. 3, Figure 2). The electrochemical processes appeared to rapidly establish and stabilize in this system having a simple hydrogeochemistry.

\subsection{Charge transfer in the electrochemical set-up}

Experimental specifications vary between studies, e.g. cross-sectional areas, flow velocities, current intensities etc. For comparison of data across studies, normalization of the experimental data is necessary. Many procedures exist for normalization. In the present study, normalization for current intensity (I), flow rate $(\mathrm{Q})$ and contaminant concentration $(\mathrm{C})$ was chosen. Flow rate was chosen instead of flow velocity to account for differences in cross-sectional areas of reactors. The output is charge transfer per contaminant mass and the lower the number, the better in terms of power consumption and thereby cost. The normalized data are plotted against PCE removal percentage (Figure 3) and compared to data reported on electrochemical removal of TCE in a similar set-up [41] (Figure 3, squares). The ratio of electrode surface area to liquid volume was different in the two experimental set-ups applied (lower in the present work) and was not optimized for in the experimental series carried out. Therefore, a deviation in levels of normalized data for a specific removal percentage obtained was expected. Figure 3 allows to compare the overall level of the normalized data obtained for electrochemical removal of PCE and TCE and the shape of the resulting curves. Note, if sequential degradation via e.g. hydrogenolysis was in progress, a fraction 
of the current supplied would be directed towards concurrent transformation of the degradation products formed. In this case, however, TCE nor DCE was detected (VC analysis was not possible), neither in Rajic et al. [41].

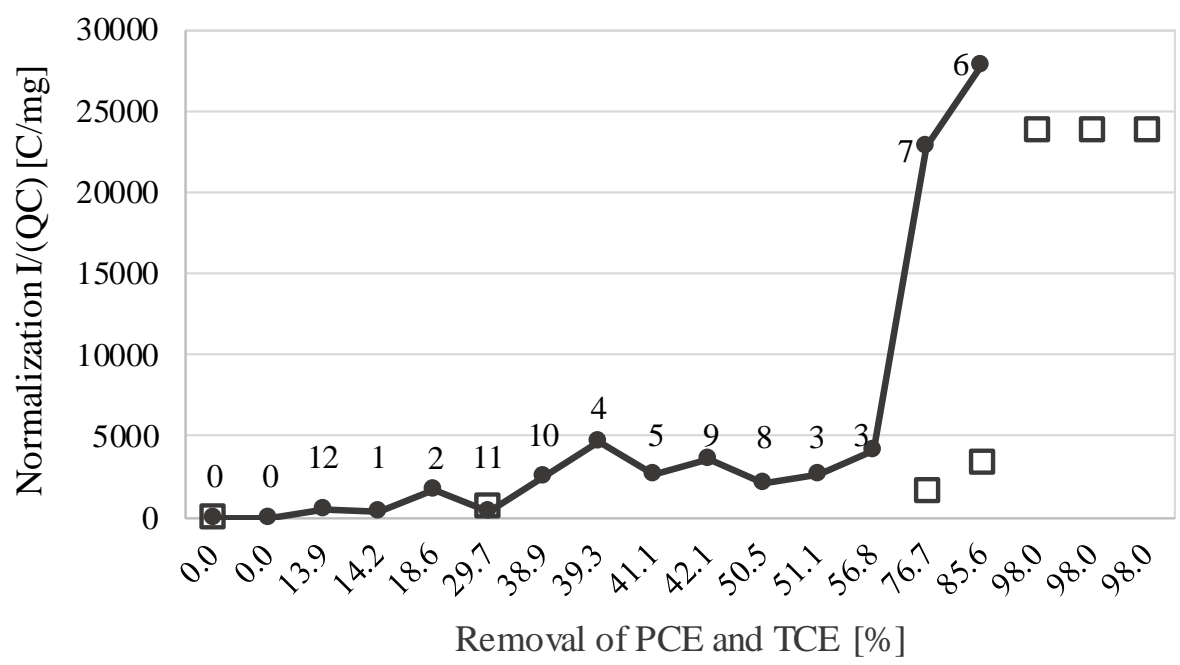

Figure 3. Normalization of experimental data for PCE based on samples extracted in the final sampling port (solid dots) and data for TCE in Rajic et al. [41] (squares) for current intensity (I), flow (Q) and contaminant concentration (C) plotted against the removal of PCE and TCE. Numbers next to markers refer to experiment number (Table 1).

For PCE removals beyond 30\%, the charge input required increased, while for TCE a similar increase appeared for removals beyond $77 \%$ (Figure 3). Thus, a higher charge transfer was required to remove PCE than TCE. The difference in electrode surface area to liquid volume ratio between the two experimental set-ups possibly contributed to the observed deviation, where the contact between contaminant, Pd catalyst on the cathode and the energy source itself is improved at a higher such ratio, enhancing the conditions for contaminant transformation at a specific charge input. A low ratio of electrode surface area to liquid volume can be compensated for by increasing the current and/or Pd load. The similar levels of normalized data for PCE and TCE at a removal of $40430 \%$ support this: MMO anodes and an electrode spacing of $2.5 \mathrm{~cm}$ were used in both set-ups. 
405 However, in the study on TCE, a Pd load of $0.76 \mathrm{mg} / \mathrm{cm}^{2}$ and a current of $60 \mathrm{~mA}$ was applied [41]. 406 In the study on PCE, having a lower electrode surface area to liquid volume, a Pd load of 1.14 $407 \mathrm{mg} / \mathrm{cm}^{2}$ and a current of $120 \mathrm{~mA}$ was applied (exp. 11). I.e. the lower electrode surface area to 408 liquid volume was counterbalanced by a $50 \%$ increase in Pd load and a $100 \%$ increase in current. A 409 further increase in current would possibly not be beneficial (exp. 4 vs. 11, Figure 2a). Instead, a 410 reduction in flow (exp. 6 vs. 11, Figure 2a) and an increase in Pd load is suggested for optimization 411 of electrochemical removal of PCE in the experimental set-up studied.

412 If comparing the normalized data obtained from all sampling ports, sampling rounds and test 413 designs (data not shown), and neglecting the associated removal levels, a generally best fit with 414 those of Rajic et al. [41] is seen when set-ups are most alike. I.e., for vertically oriented reactors 415 excluding a porous matrix (exp. 7 and 12), which illustrates the sensitivity towards the experimental 416 design. The concept of electrochemical treatment of chlorinated ethenes must be strengthened to 417 overcome the complex conditions of contaminated sites [65,73]. Finally, removals beyond app. $60 \%$ 418 and $90 \%$ for PCE and TCE, respectively, required a significant additional charge transfer, as 419 indicated by the steep slope of curves in Figure 3. Thus, treating the low levels of contaminant 420 concentrations, which is required to comply with the regulatory contaminant level for PCE and TCE 421 in drinking water, are the most expensive.

\subsection{PCE transformation pathways in the electrochemical reactor}

Mass loss is a concern when working with volatile contaminants like PCE, because it can give false positive test results and thereby incorrect foundations for decision making. Two control experiments were carried out in a set-up similar to that of experiment $1-4$, except that no current was applied (exp. 0, Table 1). No mass loss was observed throughout the 360 min of testing, 
measured downgradient the electrochemical zone (sampling port P5, exp. 0, Figure 2a). An observed drop in PCE concentration during experiments with applied current therefore is stimulated by the electrochemistry. Stripping of the contaminants due to the gas generating electrode processes (Eq. 1 and 4) rather than transformation is another concern when applying electrochemistry for removal of chlorinated ethenes. A risk especially at stable anodes like MMO, since these produce more oxygen (Eq. 5 vs. 4) [41] and PCE may be more prone to volatilization than oxidation at the anode, as opposite to the higher affinity of reduction near the cathode. The specific electrode's contribution to removal of PCE was found in the order of cathode $>$ BPE $>$ anode, indicating that electrochemically induced transformation was occurring rather than stripping. Furthermore, increasing the Pd load on the cathode from $0.76 \mathrm{mg} / \mathrm{cm}^{2}$ to $1.14 \mathrm{mg} / \mathrm{cm}^{2}$ improved the removal at $120 \mathrm{~mA}$ from $19 \%$ to $54 \pm 3 \%$ (exp. 2 vs. 3, Figure 2a), suggesting that the cathode induced processes removed PCE.

Transformation mechanisms at the cathode possibly were related to the catalytic properties of Pd through enhanced adsorption of atomic hydrogen, and thereby reductive hydrodechlorination of PCE, and/or formation of the strong oxidative species $\mathrm{H}_{2} \mathrm{O}_{2}$ and $\square \mathrm{OH}$ (Eq. 2-3). Formation of $\mathrm{H}_{2} \mathrm{O}_{2}$ and $\square \mathrm{OH}$ appeared to contribute to the transformation of PCE, since $12 \%$ more PCE was removed in the $\mathrm{C} \rightarrow \mathrm{BPE} \rightarrow \mathrm{A}$ arrangement than $\mathrm{C} \rightarrow \mathrm{C} \rightarrow \mathrm{A}$ (exp. 3 vs. 9, Figure 2a). Rajic et al. [34] showed that using a BPE in between the cathode and anode strengthened the $\mathrm{H}_{2} \mathrm{O}_{2}$ formation. This could be due to i) oxygen and dihydrogen being formed concurrently on each side of the BPE, improving the contact necessary for conversion into $\mathrm{H}_{2} \mathrm{O}_{2}$, and ii) the anodic side of the BPE facing the cathode, i.e. in closer contact and thus, if the oxygen diffused towards the cathode, it could combine with the dihydrogen generated, forming $\mathrm{H}_{2} \mathrm{O}_{2}$ at the $\mathrm{Pd}$ surface [32]. Elevated $\mathrm{pH}$ measured downstream the $\mathrm{C} \rightarrow \mathrm{BPE} \rightarrow$ A electrochemical zone (sampling port P5) indicated formation of $\mathrm{H}_{2} \mathrm{O}_{2}$ (Section 3.1). 
The sequential hydrogenolysis products TCE and DCEs were not detected in any sampling point 454 of the experiments conducted. This suggests fast concurrent hydrogenolysis of TCE and DCEs or 455 456 another transformation pathway for PCE in the electrochemical reactor, e.g. oxidation by $\mathrm{H}_{2} \mathrm{O}_{2}$ and $\square \mathrm{OH}$, and/or $\beta$-elimination [73]. In parallel to the Fe cathodes applied in this study, degradation of PCE on $\mathrm{Fe}(0)$ has shown to follow $\beta$-elimination for $87 \%$ of the contaminant mass [49]. The electrochemical mechanisms responsible for PCE transformation along with the parameters controlling those should be studied in detail for design of a robust electrochemical methodology for removal of chlorinated ethenes.

\section{Conclusion}

Protection of the groundwater resource from harmful chlorinated ethenes is crucial and challenging. Electrochemically induced reduction and oxidation may overcome some of the difficulties experienced. In the development of the method, PCE must be included in the assessment of electrochemical transformation of chlorinated ethenes, but is mostly overlooked. This study screened the significance of parameters influencing electrochemical removal of PCE in a flowthrough reactor using a palladized Fe foam cathode and an MMO mesh anode. The major findings are:

- Of the electrode configurations tested, presence of a BPE between the cathode and anode improved removal of PCE to $54 \pm 3 \%$. The BPE added an oxidizing-reducing zone and lowered the electrical resistivity.

- Pd played a major role in the transformation of PCE with a 50\% increase in Pd load on the cathode improving the removal by $36 \%$-point. 
- Increasing the electrode spacing from $2.5 \mathrm{~cm}$ to $4 \mathrm{~cm}$ enhanced the removal from $41 \%$ to $54 \pm 3 \%$, due to extension of redox zones, which is a promising trend when considering the installation and cost of field-implementation.

PCE removal in liquid flowing through an inert porous matrix was investigated to simulate insitu conditions. Presence of the porous matrix enhanced PCE removal by 9\%-point compared to a completely liquid-filled reactor due to a more complex flow pattern within the porous matrix. A horizontally orientated reactor improved PCE removal by 9-16\%-point compared to vertically oriented reactors. Release of oxygen and hydrogen gas from the electrode surfaces in the horizontal reactor was enhanced, wherefore a higher number of active electrode surface sites were available for PCE transformation. The highest removal of $86 \%$ was obtained using a horizontally oriented reactor at a current of $120 \mathrm{~mA}$ applied to an electrode configuration of $\mathrm{C} \rightarrow \mathrm{BPE} \rightarrow \mathrm{A}$ with a Pd load on the cathode of $1.14 \mathrm{mg} / \mathrm{cm}^{2}$ and a Darcy velocity of $0.03 \mathrm{~cm} / \mathrm{min}(150 \mathrm{~m} / \mathrm{yr})$ through a fully liquid-filled reactor. No chlorinated ethene degradation products were detected in any of the test designs studied.

Normalization of the data revealed, that the low contaminant concentrations were the most difficult to treat in that a significant charge transfer was required for removal beyond $60 \%$. The removal performance was found sensitive to dimensional changes in experimental reactors. The transformation mechanisms and the parameters controlling those need to be better understood to control and adjust the relevant parameters for a flexible remediation design, that can overcome the variations occurring between lab set-ups and not least at contaminated sites. Thus, this study identified some weaknesses in the current stage of development of electrochemical removal of chlorinated ethenes, but also some promising trends in conceptual designs that better simulate that of a potential field-implementation. 
501 Acknowledgements

502

503 Funding: This work was supported by the Innovation Fund Denmark [grant number 5016-00165B];

504 COWIfonden [grant number C-131.01]; the Capital Region of Denmark [grant number 14002101];

505 the Danish Ministry of Higher Education and Science [grant number 7079-00012B] and the

506 PROTECT Center under the National Institute Of Environmental Health Sciences [grant number

507 P42ES017198].The funding sources were not involved in the actual research conducted, nor in the

508 preparation of this paper.

509

510

References

511

512

[1] J.F. Pankow, S. Feenstra, J.A. Cherry, C.M. Ryan (Eds.), Dense chlorinated solvents and other DNAPLs in groundwater: History, behavior, and remediation, Waterloo Press, Portland, Oregon, 1996: pp. 1-522.

[3] A.N. Alshawabkeh, Electrokinetic soil remediation: Challenges and opportunities, Sep. Sci. Technol. 44 (2009) 2171-2187. doi:10.1080/01496390902976681.

[4] A.T. Lima, A. Hofmann, D. Reynolds, C.J. Ptacek, P. Van Cappellen, L.M. Ottosen, S. Pamukcu, A.N. Alshawabkeh, D.M. O’Carroll, C. Riis, E. Cox, D.B. Gent, R. Landis, J. Wang, A.I.A. Chowdhury, E.L. Secord, A. Sanchez-Hachair, Environmental electrokinetics for a sustainable subsurface, Chemosphere. 181 (2017) 122-133. doi:10.1016/j.chemosphere.2017.03.143. 
524 [5] K.R. Reddy, C. Cameselle (Eds.), Electrochemical remediation technologies for polluted soils, sediments and groundwater, John Wiley \& Sons, Inc., Hoboken, New Jersey, 2009: pp. $1-732$.

[6] A.B. Ribeiro, E.P. Mateus, N. Couto (Eds.), Electrokinetics across disciplines and continents, new strategies for sustainable development, Springer International Publishing, London, 2016: pp. 1-469. doi:10.1007/978-3-319-20179-5.

[7] H.F. Stroo, C.H. Ward (Eds.), In situ remediation of chlorinated solvent plumes, Springer, New York, NY, 2010: pp. 1-786. doi:10.1007/978-1-4419-1401-9.

[8] M.J. Moran, J.S. Zogorski, P.J. Squillace, Chlorinated solvents in groundwater of the United States, Environ. Sci. Technol. 41 (2007) 74-81. doi:10.1021/es061553y.

[9] D.M. Mackay, J.A. Cherry, Groundwater contamination: Pump-and-treat remediation, Environ. Sci. Technol. 23 (1989) 630-636. doi:10.1021/es00064a001.

[10] Interstate Technology \& Regulatory Council, Integrated DNAPL site strategy, Washington, DC, USA, 2011: pp. 1-209. http://www.itrcweb.org.

[11] B.H. Kueper, H.F. Stroo, C.M. Vogel, C.H. Ward (Eds.), Chlorinated solvent source zone remediation, Springer, New York, USA, 2014: pp. 1-759. doi:10.1007/978-1-4614-6922-3.

[12] R.L. Siegrist, M. Crimi, M.M. Broholm, J.E. McCray, T.H. Illangasekare, P.L. Bjerg, Advances in groundwater remediation: Achieving effective in situ delivery of chemical oxidants and amendments, in: F.F. Quercia, D. Vidojevic (Eds.), Clean Soil Safe Water, Springer, Dordrecht, The Netherlands, 2012: pp. 197-212. doi:10.1007/978-94-007-2240$8 \_22$.

[13] Interstate Technology \& Regulatory Council, Permeable reactive barriers: Lessons learned/new directions. PRB-4, Washington, DC, USA, 2005: pp. 1-202.

[14] Y.T. He, J.T. Wilson, C. Su, R.T. Wilkin, Review of abiotic degradation of chlorinated 
solvents by reactive iron minerals in aquifers, Groundw. Monit. Remediat. 35 (2015) 57-75. doi:10.1111/gwmr.12111.

[15] D.H. Bass, N.A. Hastings, R.A. Brown, Performance of air sparging systems: a review of case studies, J. Hazard. Mater. 72 (2000) 101-119. doi:10.1016/S0304-3894(99)00136-3.

[16] M.H. Stenzel, U. Sen Gupta, Treatment of contaminated groundwaters with granular activated carbon and air stripping, J. Air Pollut. Control Assoc. 35 (1985) 1304-1309. doi:10.1080/00022470.1985.10466035.

[17] H.F. Stroo, A. Leeson, J.A. Marqusee, P.C. Johnson, C.H. Ward, M.C. Kavanaugh, T.C. Sale, C.J. Newell, K.D. Pennell, C.A. Lebrón, M. Unger, Chlorinated ethene source remediation: Lessons learned, Environ. Sci. Technol. 46 (2012) 6438-6447. doi:10.1021/es204714w.

[18] C. Scheutz, M.M. Broholm, N.D. Durant, E.B. Weeth, T.H. Jørgensen, P. Dennis, C.S. Jacobsen, E.E. Cox, J.C. Chambon, P.L. Bjerg, Field evaluation of biological enhanced reductive dechlorination of chloroethenes in clayey till, Environ. Sci. Technol. 44 (2010) 5134-5141. doi:10.1021/es1003044.

[19] F. Aulenta, A. Pera, S. Rossetti, M. Petrangeli Papini, M. Majone, Relevance of side reactions in anaerobic reductive dechlorination microcosms amended with different electron donors, Water Res. 41 (2007) 27-38. doi:10.1016/j.watres.2006.09.019.

[20] D. O’Connor, D. Hou, Y.S. Ok, Y. Song, A.K. Sarmah, X. Li, F.M.G. Tack, Sustainable in situ remediation of recalcitrant organic pollutants in groundwater with controlled release materials: A review, J. Control. Release. 283 (2018) 200-213. doi:10.1016/j.jconrel.2018.06.007.

[21] K. Urano, E. Yamamoto, M. Tonegawa, K. Fujie, Adsorption of chlorinated organic compounds on activated carbon from water, Water Res. 25 (1991) 1459-1464. 
doi:10.1016/j.arabjc.2015.04.013.

[22] X. Mao, A. Ciblak, M. Amiri, A.N. Alshawabkeh, Redox control for electrochemical dechlorination of trichloroethylene in bicarbonate aqueous media, Environ. Sci. Technol. 45 (2011) 6517-6523. doi:10.1021/es200943z.

[23] X. Mao, A. Ciblak, K. Baek, M. Amiri, R. Loch-Caruso, A.N. Alshawabkeh, Optimization of electrochemical dechlorination of trichloroethylene in reducing electrolytes, Water Res. 46 (2012) 1847-1857. doi:10.1016/j.watres.2012.01.002.

[24] X. Mao, S. Yuan, N. Fallahpour, A. Ciblak, J. Howard, I. Padilla, R. Loch-Caruso, A.N. Alshawabkeh, Electrochemically induced dual reactive barriers for transformation of TCE and mixture of contaminants in groundwater, Environ. Sci. Technol. 46 (2012) 1200312011. doi:10.1021/es301711a.

[25] P.H. Fallgren, J.J. Eisenbeis, S. Jin, In situ electrochemical manipulation of oxidationreduction potential in saturated subsurface matrices, J. Environ. Sci. Heal. Part A. 53 (2018) 517-523. doi:10.1080/10934529.2017.1422951.

[26] Y.B. Acar, A.N. Alshawabkeh, Principles of electrokinetic remediation, Environ. Sci. Technol. 27 (1993) 2638-2647. doi:10.1021/es00049a002.

[27] M. Zheng, J. Bao, P. Liao, K. Wang, S. Yuan, M. Tong, H. Long, Electrogeneration of H2 for Pd-catalytic hydrodechlorination of 2,4-dichlorophenol in groundwater, Chemosphere. 87 (2012) 1097-1104. doi:10.1016/j.chemosphere.2012.01.058.

[28] F. Aulenta, L. Tocca, R. Verdini, P. Reale, M. Majone, Dechlorination of trichloroethene in a continuous-flow bioelectrochemical reactor: Effect of cathode potential on rate, selectivity, and electron transfer mechanisms, Environ. Sci. Technol. 45 (2011) 8444-8451. doi:10.1021/es202262y.

[29] R. Verdini, F. Aulenta, F. de Tora, A. Lai, M. Majone, Relative contribution of set cathode 
potential and external mass transport on TCE dechlorination in a continuous-flow bioelectrochemical reactor, Chemosphere. 136 (2015) 72-78.

doi:10.1016/j.chemosphere.2015.03.092.

[30] S.T. Lohner, D. Becker, K.M. Mangold, A. Tiehm, Sequential reductive and oxidative biodegradation of chloroethenes stimulated in a coupled bioelectro-process, Environ. Sci. Technol. 45 (2011) 6491-6497. doi:10.1021/es200801r.

[31] F. Aulenta, R. Verdini, M. Zeppilli, G. Zanaroli, F. Fava, S. Rossetti, M. Majone, Electrochemical stimulation of microbial cis-dichloroethene (cis-DCE) oxidation by an ethene-assimilating culture, N. Biotechnol. 30 (2013) 749-755. doi:10.1016/j.nbt.2013.04.003.

[32] S. Yuan, M. Chen, X. Mao, A.N. Alshawabkeh, A three-electrode column for Pd-catalytic oxidation of TCE in groundwater with automatic $\mathrm{pH}$-regulation and resistance to reduced sulfur compound foiling, Water Res. 47 (2013) 269-278. doi:10.1016/j.watres.2012.10.009.

[33] W. Zhou, L. Rajic, Y. Zhao, J. Gao, Y. Qin, A.N. Alshawabkeh, Rates of H2O2 electrogeneration by reduction of anodic $\mathrm{O} 2$ at RVC foam cathodes in batch and flowthrough cells, Electrochim. Acta. 277 (2018) 185-196. doi:10.1016/j.electacta.2018.04.174.

[34] L. Rajic, R. Nazari, N. Fallahpour, A.N. Alshawabkeh, Electrochemical degradation of trichloroethylene in aqueous solution by bipolar graphite electrodes, J. Environ. Chem. Eng. 4 (2016) 197-202. doi:10.1016/j.jece.2015.10.030.

[35] P. Lakshmipathiraj, G. Bhaskar Raju, Y. Sakai, Y. Takuma, A. Yamasaki, S. Kato, T. Kojima, Studies on electrochemical detoxification of trichloroethene (TCE) on Ti/IrO2Ta2O5 electrode from aqueous solution, Chem. Eng. J. 198-199 (2012) 211-218. doi:10.1016/j.cej.2012.05.092.

[36] B. Liu, H. Zhang, Q. Lu, G. Li, F. Zhang, A Cu Ni bimetallic cathode with nanostructured 
copper array for enhanced hydrodechlorination of trichloroethylene (TCE), Sci. Total Environ. 635 (2018) 1417-1425. doi:10.1016/j.scitotenv.2018.04.238.

[37] S. Yuan, X. Mao, A.N. Alshawabkeh, Efficient degradation of TCE in groundwater using Pd and electro-generated $\mathrm{H} 2$ and $\mathrm{O} 2$ : A shift in pathway from hydrodechlorination to oxidation in the presence of ferrous ions, Environ. Sci. Technol. 46 (2012) 3398-3405. doi:10.1021/es204546u.

[38] W. Xie, S. Yuan, X. Mao, W. Hu, P. Liao, M. Tong, A.N. Alshawabkeh, Electrocatalytic activity of Pd-loaded Ti/TiO2 nanotubes cathode for TCE reduction in groundwater, Water Res. 47 (2013) 3573-3582. doi:10.1016/j.watres.2013.04.004.

[39] M.A. Petersen, T.C. Sale, K.F. Reardon, Electrolytic trichloroethene degradation using mixed metal oxide coated titanium mesh electrodes, Chemosphere. 67 (2007) 1573-1581. doi:10.1016/j.chemosphere.2006.11.056.

[40] N. Fallahpour, S. Yuan, L. Rajic, A.N. Alshawabkeh, Hydrodechlorination of TCE in a circulated electrolytic column at high flow rate, Chemosphere. 144 (2016) 59-64. doi:10.1016/j.chemosphere.2015.08.037.

[41] L. Rajic, N. Fallahpour, A.N. Alshawabkeh, Impact of electrode sequence on electrochemical removal of trichloroethylene from aqueous solution, Appl. Catal. B Environ. 174-175 (2015) 427-434. doi:10.1016/j.apcatb.2015.03.018.

[42] L. Rajic, N. Fallahpour, E. Podlaha, A.N. Alshawabkeh, The influence of cathode material on electrochemical degradation of trichloroethylene in aqueous solution, Chemosphere. 147 (2016) 98-104. doi:10.1016/j.chemosphere.2015.12.095.

[43] L. Rajic, N. Fallahpour, R. Nazari, A.N. Alshawabkeh, Influence of humic substances on electrochemical degradation of trichloroethylene in limestone aquifers, Electrochim. Acta. 181 (2015) 123-129. doi:10.1016/j.electacta.2015.03.121. 
[44] L. Rajic, N. Fallahpour, S. Yuan, A.N. Alshawabkeh, Electrochemical transformation of trichloroethylene in aqueous solution by electrode polarity reversal, Water Res. 67 (2014) 267-275. doi:10.1016/j.watres.2014.09.017.

[45] R.W. Gillham, S.F. O’Hannesin, Enhanced degradation of halogenated aliphatics by zerovalent iron, Ground Water. 32 (1994) 958-967. doi:10.1111/j.1745-6584.1994.tb00935.x.

[46] T.L. Johnson, M.M. Scherer, P.G. Tratnyek, Kinetics of halogenated organic compound degradation by iron metal, Environ. Sci. Technol. 30 (1996) 2634-2640. doi:10.1021/es9600901.

[47] M.M. Scherer, B.A. Balko, D.A. Gallagher, P.G. Tratnyek, Correlation analysis of rate constants for dechlorination by zero-valent iron, Environ. Sci. Technol. 32 (1998) 30263033. doi:10.1021/es9802551.

[48] E.C. Butler, K.F. Hayes, Kinetics of the transformation of trichloroethylene and tetrachloroethylene by iron sulfide, Environ. Sci. Technol. 33 (1999) 2021-2027. doi:10.1021/es9809455.

[49] W.A. Arnold, A.L. Roberts, Pathways and kinetics of chlorinated ethylene and chlorinated acetylene reaction with Fe(0) particles, Environ. Sci. Technol. 34 (2000) 1794-1805. doi:10.1021/es980252o.

[50] Y.H. Kim, E.R. Carraway, Dechlorination of chlorinated ethenes and acetylenes by palladized iron, Environ. Technol. 24 (2003) 809-819. doi:10.1080/09593330309385618.

[51] J. Farrell, N. Melitas, M. Kason, T. Li, Electrochemical and column investigation of ironmediated reductive dechlorination of trichloroethylene and perchloroethylene, Environ. Sci. Technol. 34 (2000) 2549-2556. doi:10.1021/es991135b.

[52] T. Li, J. Farrell, Electrochemical investigation of the rate-limiting mechanisms for trichloroethylene and carbon tetrachloride reduction at iron surfaces, Environ. Sci. Technol. 
35 (2001) 3560-3565. doi:10.1021/es0019878.

[53] W.F. Wüst, R. Köber, O. Schlicker, A. Dahmke, Combined zero- and first-order kinetic model of the degradation of tce and cis-DCE with commercial iron, Environ. Sci. Technol. 33 (1999) 4304-4309. doi:10.1021/es980439f.

[54] C. Su, R.W. Puls, Kinetics of trichloroethene reduction by zerovalent iron and tin: Pretreatment effect, apparent activation energy, and intermediate products, Environ. Sci. Technol. 33 (1999) 163-168. doi:10.1021/es980481a.

[55] L. Rajic, N. Fallahpour, E. Oguzie, A.N. Alshawabkeh, Electrochemical transformation of thichloroethylene in groundwater by Ni-containing cathodes, Electrochim. Acta. 181 (2015) 118-122. doi:10.1016/j.electacta.2015.03.112.

[56] S. Yuan, M. Chen, X. Mao, A.N. Alshawabkeh, Effects of reduced sulfur compounds on Pdcatalytic hydrodechlorination of trichloroethylene in groundwater by cathodic $\mathrm{H} 2$ under electrochemically induced oxidizing conditions, Environ. Sci. Technol. 47 (2013) 1050210509. doi:10.1021/es402169d.

[57] V. Sáez, M.D. Esclapez Vicente, Á.J. Frías-Ferrer, P. Bonete, J. González-García, Electrochemical degradation of perchloroethylene in aqueous media: An approach to different strategies, Water Res. 43 (2009) 2169-2178. doi:10.1016/j.watres.2009.02.019.

[58] N. Fallahpour, X. Mao, L. Rajic, S. Yuan, A.N. Alshawabkeh, Electrochemical dechlorination of trichloroethylene in the presence of natural organic matter, metal ions and nitrates in a simulated karst media, J. Environ. Chem. Eng. 5 (2017) 240-245. doi:10.1016/j.jece.2016.11.046.

[59] O. Scialdone, C. Guarisco, A. Galia, R. Herbois, Electroreduction of aliphatic chlorides at silver cathodes in water, J. Electroanal. Chem. 641 (2010) 14-22. doi:10.1016/j.jelechem.2010.01.018. 
[60] T. Li, J. Farrell, Reductive dechlorination of trichloroethene and carbon tetrachloride using iron and palladize-iron cathodes, Environ. Sci. Technol. 34 (2000) 173-179.

[61] A. Tiehm, S.T. Lohner, T. Augenstein, Effects of direct electric current and electrode reactions on vinyl chloride degrading microorganisms, Electrochim. Acta. 54 (2009) 34533459. doi:10.1016/j.electacta.2009.01.002.

[62] F. Aulenta, A. Canosa, P. Reale, S. Rossetti, S. Panero, M. Majone, Microbial reductive dechlorination of trichloroethene to ethene with electrodes serving as electron donors without the external addition of redox mediators, Biotechnol. Bioeng. 103 (2009) 85-91. doi:10.1002/bit.22234.

[63] F. Aulenta, P. Reale, A. Canosa, S. Rossetti, S. Panero, M. Majone, Characterization of an electro-active biocathode capable of dechlorinating trichloroethene and cis-dichloroethene to ethene, Biosens. Bioelectron. 25 (2010) 1796-1802. doi:10.1016/j.bios.2009.12.033.

[64] A. Lai, R. Verdini, F. Aulenta, M. Majone, Influence of nitrate and sulfate reduction in the bioelectrochemically assisted dechlorination of cis-DCE, Chemosphere. 125 (2015) 147-154. doi:10.1016/j.chemosphere.2014.12.023.

[65] B.H. Hyldegaard, R. Jakobsen, E.B. Weeth, N.D. Overheu, D.B. Gent, L.M. Ottosen, Challenges in electrochemical remediation of chlorinated solvents in natural groundwater aquifer settings, J. Hazard. Mater. 368 (2019) 680-688. doi:10.1016/j.jhazmat.2018.12.064.

[66] J.H. Brewster, Mechanisms of reductions at metal surfaces. I. A general working hypothesis, J. Am. Chem. Soc. 76 (1954) 6361-6363. doi:10.1021/ja01653a034.

[67] G. Chen, Electrochemical technologies in wastewater treatment, Sep. Purif. Technol. 38 (2004) 11-41. doi:10.1016/j.seppur.2003.10.006.

[68] D. Ghosh, C.R. Medhi, H. Solanki, M.K. Purkait, Decolorization of crystal violet solution by electrocoagulation, J. Environ. Prot. Sci. 2 (2008) 25-35. 
[69] T. Umemura, K. Sato, Y. Kusaka, H. Satoh, Palladium, in: G. Nordber, B. Fowler, M. Nordberg (Eds.), Handbook on the toxicology of metals 4E, Academic Press, 2015: pp. 1113-1123. doi:10.1016/B978-0-444-59453-2.00049-4.

[70] A. Okamoto, M. Yamamuro, N. Tatarazako, Acute toxicity of 50 metals to Daphnia magna, J. Appl. Toxicol. 35 (2015) 824-830. doi:10.1002/jat.3078.

[71] S. Lüderwald, F. Seitz, G.. Seisenbaeva, V.. Kessler, R. Schulz, M. Bundschuh, Palladium nanoparticles: Is there a risk for aquatic ecosystems?, Bull. Environ. Contam. Toxicol. 97 (2016) 153-158. doi:10.1007/s00128-016-1803-x.

[72] L. Gabrieli, A.N. Alshawabkeh, Influence of boundary conditions on transient excess pore pressure during electrokinetic applications in soils, J. Appl. Electrochem. 40 (2010) 11131121. doi:10.1007/s10800-010-0075-0.

[73] L.M. Ottosen, T.H. Larsen, P.E. Jensen, G.M. Kirkelund, H. Kerrn-Jespersen, N. Tuxen, B.H. Hyldegaard, Electrokinetics applied in remediation of subsurface soil contaminated with chlorinated ethenes - A review, Chemosphere. 235 (2019) 113-125. doi:10.1016/j.chemosphere.2019.06.075. 
Click here to download Table: Table 1_Bente H Hyldegaard_November 2019.docx

Table 1. Experimental conditions for the electrochemical treatment of initially $2.7 \mathrm{mg} / \mathrm{l} \mathrm{PCE}$.

\begin{tabular}{|c|c|c|c|c|c|c|c|c|}
\hline & $\begin{array}{c}\text { Electrode } \\
\text { configuration }^{\mathrm{a}}\end{array}$ & Electrode material & $\begin{array}{c}\text { Electrode } \\
\text { spacing } \\
{[\mathrm{cm}]}\end{array}$ & $\begin{array}{l}\text { Column } \\
\text { orientation }\end{array}$ & $\begin{array}{l}\text { Current } \\
{[\mathrm{mA}]}\end{array}$ & $\begin{array}{c}\text { Pd catalyst } \\
\text { loading } \\
{\left[\mathrm{mg} / \mathrm{cm}^{2}\right]}\end{array}$ & $\begin{array}{c}\text { Darcy } \\
\text { velocity } \\
{[\mathrm{cm} / \mathrm{min}]}\end{array}$ & $\begin{array}{c}\text { Porosity, } \\
\text { water- } \\
\text { filled }^{\mathrm{c}}[\%]\end{array}$ \\
\hline $0^{\mathrm{d}}$ & $\mathrm{C} \rightarrow \mathrm{BPE} \rightarrow \mathrm{A}$ & $\mathrm{Fe}$ foam $\rightarrow \mathrm{MMO} \rightarrow \mathrm{MMO}$ & 4 & Horizontal & 0 & 0.76 & 0.09 & $31.1 \pm 0.3$ \\
\hline 1 & $\mathrm{C} \rightarrow \mathrm{BPE} \rightarrow \mathrm{A}$ & $\mathrm{Fe}$ foam $\rightarrow \mathrm{MMO} \rightarrow \mathrm{MMO}$ & 4 & Horizontal & 60 & 0.76 & 0.09 & 30.8 \\
\hline 2 & $\mathrm{C} \rightarrow \mathrm{BPE} \rightarrow \mathrm{A}$ & $\mathrm{Fe}$ foam $\rightarrow \mathrm{MMO} \rightarrow \mathrm{MMO}$ & 4 & Horizontal & 120 & 0.76 & 0.09 & 30.8 \\
\hline $3^{d}$ & $\mathrm{C} \rightarrow \mathrm{BPE} \rightarrow \mathrm{A}$ & $\mathrm{Fe}$ foam $\rightarrow \mathrm{MMO} \rightarrow \mathrm{MMO}$ & 4 & Horizontal & 120 & 1.14 & 0.08 & $34.8 \pm 0.5$ \\
\hline 4 & $\mathrm{C} \rightarrow \mathrm{BPE} \rightarrow \mathrm{A}$ & $\mathrm{Fe}$ foam $\rightarrow \mathrm{MMO} \rightarrow \mathrm{MMO}$ & 4 & Horizontal & 180 & 1.14 & 0.08 & 35.3 \\
\hline 5 & $\mathrm{C} \rightarrow \mathrm{BPE} \rightarrow \mathrm{A}$ & $\mathrm{Fe}$ foam $\rightarrow \mathrm{MMO} \rightarrow \mathrm{MMO}$ & 2.5 & Horizontal & 120 & 1.14 & 0.08 & 34.1 \\
\hline 6 & $\mathrm{C} \rightarrow \mathrm{BPE} \rightarrow \mathrm{A}$ & $\mathrm{Fe}$ foam $\rightarrow \mathrm{MMO} \rightarrow \mathrm{MMO}$ & 4 & Horizontal & 120 & 1.14 & 0.03 & 100 \\
\hline 7 & $\mathrm{C} \rightarrow \mathrm{BPE} \rightarrow \mathrm{A}$ & $\mathrm{Fe}$ foam $\rightarrow \mathrm{MMO} \rightarrow \mathrm{MMO}$ & 4 & Vertical & 120 & 1.14 & 0.03 & 100 \\
\hline 8 & $\mathrm{C} \rightarrow \mathrm{C} \rightarrow \mathrm{A}$ & $\mathrm{SS} \rightarrow \mathrm{Fe}$ foam $\rightarrow \mathrm{MMO}$ & 4 & Horizontal & 120 & 1.14 & 0.08 & 34.2 \\
\hline 9 & $\mathrm{C} \rightarrow \mathrm{C} \rightarrow \mathrm{A}$ & $\mathrm{Fe}$ foam $\rightarrow \mathrm{Fe}$ foam $\rightarrow \mathrm{MMO}$ & 4 & Horizontal & 120 & 1.14 & 0.08 & 35.0 \\
\hline 10 & $\mathrm{C} \rightarrow \mathrm{A}$ & $\mathrm{Fe}$ foam $\rightarrow \mathrm{MMO}$ & 8 & Horizontal & 120 & 1.14 & 0.08 & 34.3 \\
\hline 11 & $\mathrm{C} \rightarrow \mathrm{A}$ & $\mathrm{Fe}$ foam $\rightarrow \mathrm{MMO}$ & 2.5 & Horizontal & 120 & 1.14 & 0.25 & 100 \\
\hline 12 & $\mathrm{C} \rightarrow \mathrm{A}$ & $\mathrm{Fe}$ foam $\rightarrow \mathrm{MMO}$ & 2.5 & Vertical & 120 & 1.14 & 0.25 & 100 \\
\hline
\end{tabular}

\footnotetext{
${ }^{\mathrm{a}}$ A: Anode, C: Cathode, BPE: Bipolar electrode

${ }^{\mathrm{b}}$ Catalyst applied on Fe foam only. Load is given as mass per geometric electrode surface area

${ }^{\mathrm{c}}$ Porosities of $100 \%$ indicate a fully liquid-filled reactor, while tests with porosities $<100 \%$ incorporate the porous matrix

${ }^{\mathrm{d}}$ Duplicate testing
} 


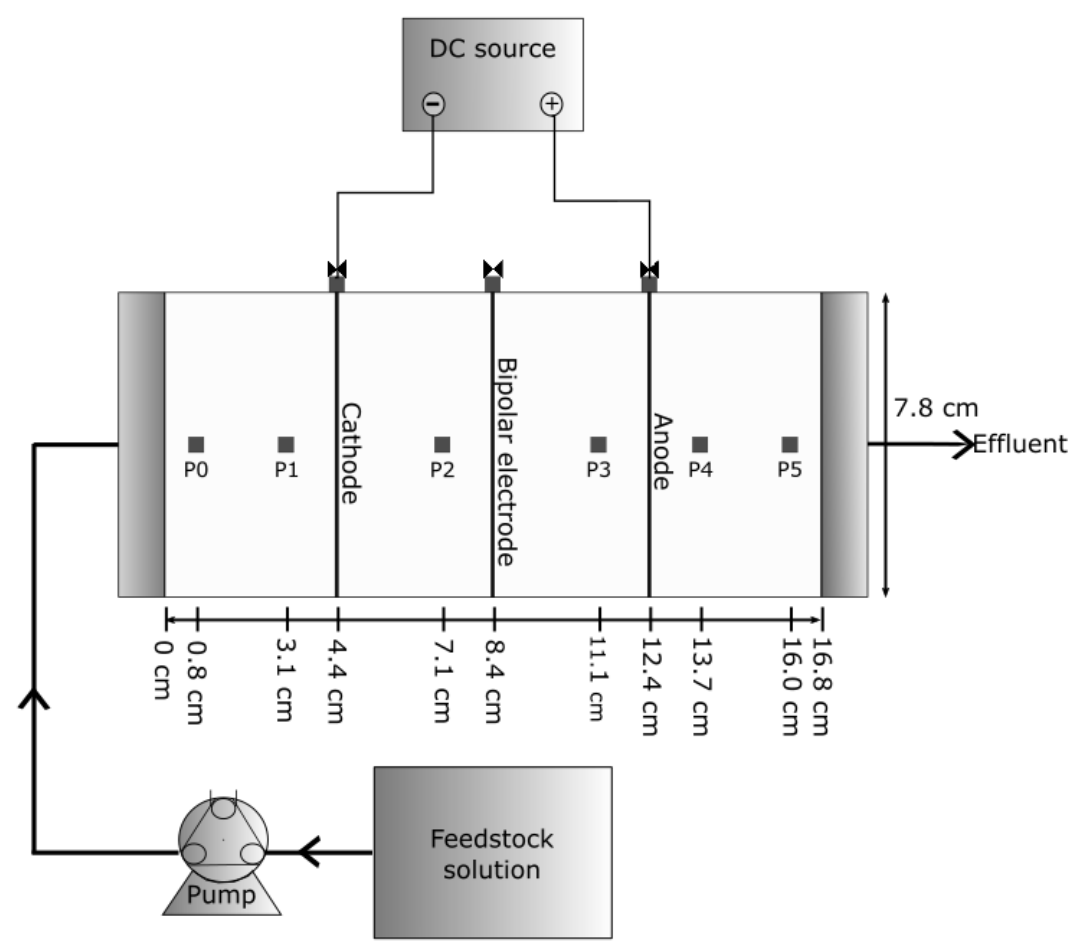

Figure 1. The baseline flow-through electrochemical set-up composed of a feedstock solution, peristaltic pump, a cathode, bipolar electrode and an anode connected to a DC source. P0-P5 are sampling ports. Sampling ports above the electrodes served for manual extraction of gases generated. Measures are of inner dimensions. 

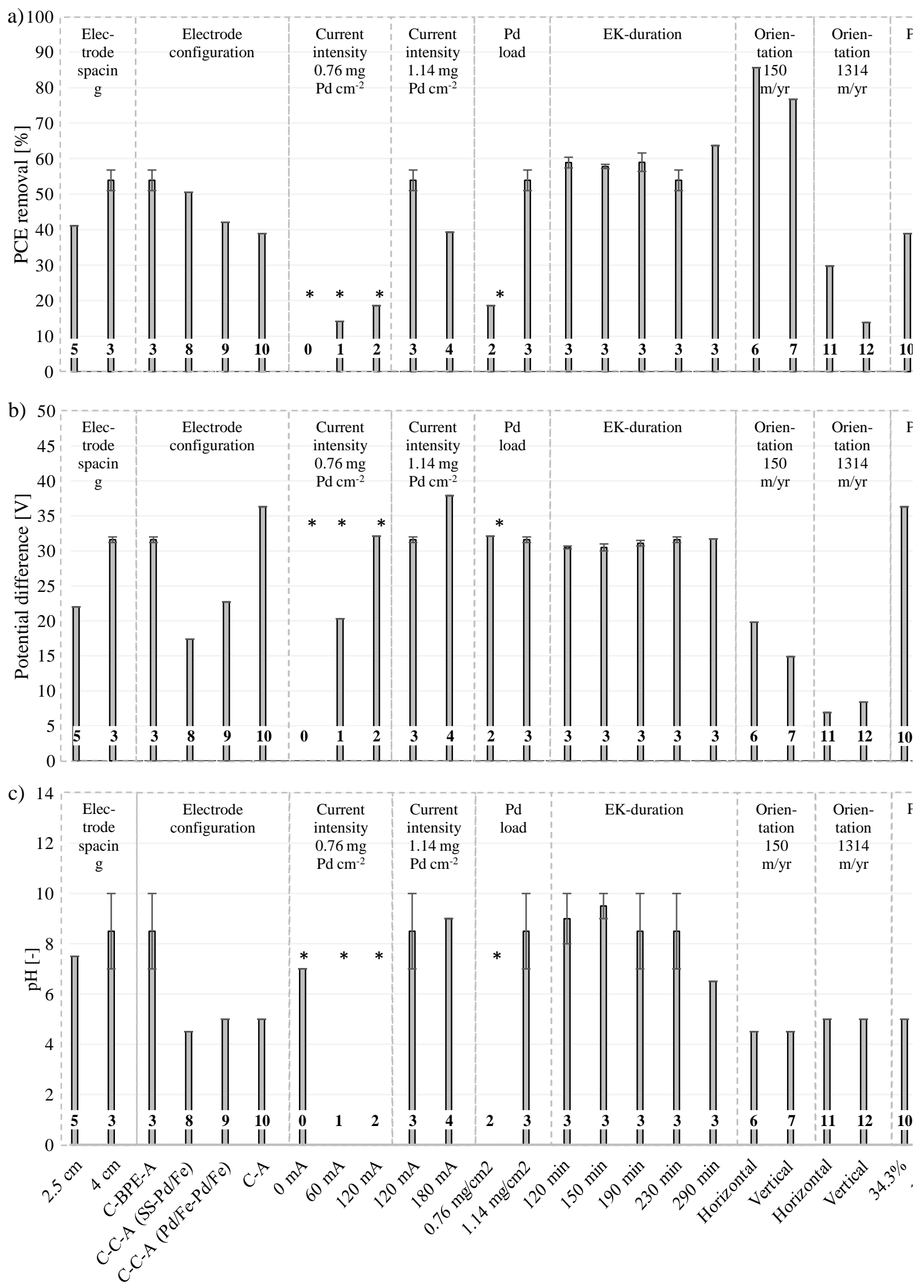


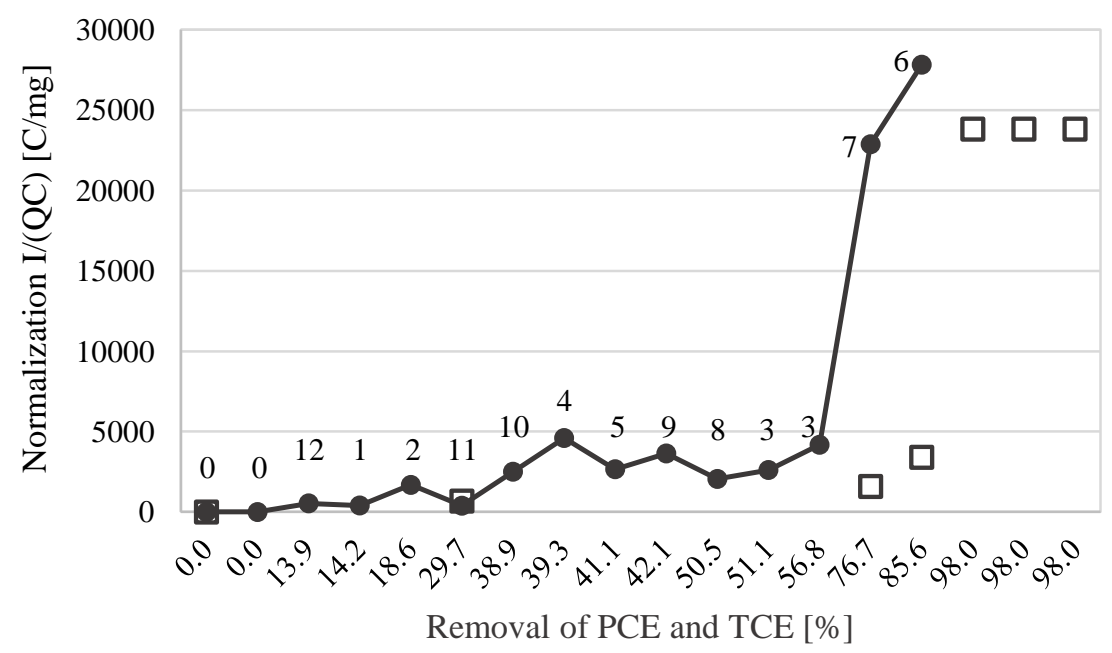

Figure 3. Normalization of experimental data for PCE based on samples extracted in the final sampling port (solid dots) and data for TCE in Rajic et al. [25] (squares) for current intensity (I), flow (Q) and contaminant concentration (C) plotted against the removal of PCE and TCE. Numbers next to markers refer to experiment number (Table 1). 